\title{
CULTURA DE PAZ COMO COMPONENTE DA LEI DE DIRETRIZES E BASES DA EDUCAÇÃO NACIONAL: DILEMAS E POSSIBILIDADES
}

\author{
CULTURE OF PEACE AS A COMPONENT OF THE LAW OF GUIDELINES \\ AND BASES OF NATIONAL EDUCATION: DILEMMAS AND POSSIBILITIES
}

\author{
Nei Alberto Salles Filho* \\ Virgínia Ostroski Salles ${ }^{* *}$
}

\begin{abstract}
RESUMO
Este artigo objetiva discutir a inclusão do tema Cultura de Paz no âmbito da Lei nº . 9.394/96, a Lei de Diretrizes e Bases da Educação Nacional brasileira. A referida alteração se deu em maio de 2018 e traz consigo a necessidade de considerar tensões teóricas e metodológicas referentes ao tema. Embora inicialmente seja uma ideia positiva, é fundamental discutir os desdobramentos, dilemas e possibilidades que a Cultura de Paz traz ao universo escolar, sob o risco de ter suas práticas pedagógicas esvaziadas de sentido ou tratadas na perspectiva do senso comum. Para pensar destas questões, discutimos elementos relacionados à Educação para a Paz como campo de conhecimento teórico estabelecido, tanto em suas bases conceituais como nas perspectivas metodológicas. Ao final, estabelecemos a relação das questões tratadas com uma proposta teórico-metodológica estabelecida para a realidade escolar brasileira.
\end{abstract}

Palavras-chave: Educação. Cultura de Paz. Educação para a Paz. Pedagogias da Paz.

\begin{abstract}
This article aims to discuss the inclusion of the theme Culture of Peace in the scope of Law No. 9.394/96, the Law of Guidelines and Bases of Brazilian National Education. This change occurred in May 2018 and brings with it the need to consider theoretical and methodological tensions related to the theme. Although initially a positive idea, it is fundamental to discuss the unfolding, dilemmas and possibilities that the Culture of Peace brings to the school universe, at the risk of having its pedagogical practices devoid of meaning or treated in the perspective of common sense. In order to think about these issues, we discuss elements related to Education for Peace as a theoretical field of knowledge, both in its conceptual bases and in the methodological perspectives. In the end, we established the relationship of the issues treated with a theoretical-methodological proposal established for the Brazilian school reality.
\end{abstract}

Keywords: Education. Culture of Peace. Education for Peace. Pedagogies of Peace.

\footnotetext{
"Doutor em Educação. Mestre em Educação. Docente do Programa de Pós-Graduação em Ciências Sociais Aplicadas (PPGCSA/UEPG) e do Curso de Educação Física (UEPG). Áreas de interesse: Direitos Humanos, Educação. Cultura de Paz e Violências. Epistemologia, Educação Física Escolar.

** Doutoranda no Programa de Pós-Graduação em Ensino de Ciência e Tecnologia na Universidade Tecnológica Federal do Paraná, Campus Ponta Grossa. Bolsista CAPES. Membro do Núcleo de Estudos e Formação de Professores em Educação para a Paz e Convivências. E-mail: virginia.utfpr@gmail.com
} 


\section{DO ÂMBITO GERAL DA DISCUSSÃO}

Em 14 de maio de 2018 foi sancionada, pela presidência da República do Brasil, a Lei no . 13.663, que alterou o artigo 12 da Lei de Diretrizes e Bases da Educação Nacional (LEI Nº 9.394/96), no sentido de incluir medidas de combate à violência e a promoção da cultura de paz nos estabelecimentos de ensino. Com esta alteração, foram inseridos dois incisos, com a seguinte redação:

IX - promover medidas de conscientização, de prevenção e de combate a todos os tipos de violência, especialmente à intimidação sistemática (bullying), no âmbito das escolas;

$\mathrm{X}$ - estabelecer ações destinadas a promover a cultura de paz nas escolas.

Sobre esta inserção, na lei maior da educação do país, é importante ressaltar que não foi uma medida ao acaso, intempestiva ou um lobby de grupos específicos. A discussão sobre a violência nas escolas veio ganhando corpo ao longo da última década no país, devido aos elevados índices referentes à agressão, bullying e até de assassinatos nos estabelecimentos de ensino. Ao mesmo tempo em que os dados são reveladores da violência social refletida nas escolas, notamos que também existe toda uma violência escolar própria. Neste sentido, anteriormente à mudança na lei, já havia a garantia de espaço aos temas sobre violência e Cultura de Paz no Plano Nacional de Educação (PNE) 2014-2024 (LEI No. 13.005/14) com a seguinte redação:

[...] garantir políticas de combate à violência na escola, inclusive pelo desenvolvimento de ações destinadas à capacitação de educadores para detecção dos sinais de suas causas, como a violência doméstica e sexual, favorecendo a adoção das providências adequadas para promover a construção da cultura de paz e um ambiente escolar dotado de segurança para a comunidade.

Deste modo, o PNE oportunizou que os Estados e Municípios, ao organizarem seus próprios planos estaduais e municipais (até 2016), inserissem os temas em suas agendas educacionais. Para reforçar esta perspectiva houve, em 2015, a aprovação da Lei $\mathrm{n}^{\mathrm{o}}$. 13.185, que instituiu o Programa de Combate à Intimidação Sistemática (Bullying) em território nacional. Além disso, cabe arrolar nesta discussão, a perspectiva da Educação em Direitos Humanos, já presente na discussão educacional brasileira, desde a primeira década do século XXI, culminando com o lançamento das Diretrizes Nacionais da Educação em Direitos Humanos, publicadas em 2013. Se considerarmos que cada um destes processos é fruto de dezenas e centenas de grupos, desde a mobilização pelos direitos humanos, até o combate ao bullying e a Cultura de Paz como pano de fundo, por diversos segmentos profissionais, além de movimentos sociais e representações religiosas, notamos que houve grande esforço para que a mudança da lei fosse efetivada. Ao mesmo tempo que esta diversidade fortaleceu o movimento de combate a violência escolar, talvez seja, ao mesmo tempo, o maior desafio ao pensar nas bases mínimas para uma Cultura de Paz na escola, com um viés educacional, crítico, criativo e laico.

Neste artigo, vamos discutir especificamente a questão da Cultura de Paz incluída na Lei nº . 9.394/96, devido à necessidade de esclarecer conceitos e experiências que permitam estruturar ações escolares concretas nesta área. A partir desta constatação argumentamos que uma Educação para a Paz, como o campo pedagógico da Cultura de Paz, se encontra justamente no interior das relações entre a violência (em suas múltiplas formas), os conflitos (em suas diferentes manifestações) e a paz (com suas acepções diversas). Com isso, dizemos que as abordagens sobre a paz nas escolas, se não vierem acompanhadas de uma dimensão conceitual mínima, nestes três campos, tem seu potencial reduzido em termos de sustentabilidade em programas e projetos, pois poderão ficar concentradas em apenas um destes aspectos. Exemplos: um projeto de valores humanos que fale dos valores "universais", mas que não exponha a desigualdade social que influencia na própria percepção de valores; um projeto de mediação de conflitos que seja conduzido de maneira autoritária; um projeto de meio ambiente que fale de árvores sem tratar do esgotamento dos recursos do planeta ou ainda, a clássica imagem das pombinhas brancas da paz pelos corredores da escola.

Certamente não negamos nenhuma destas ações, ao contrário, são as tentativas legítimas de melhorar o clima escolar, prevenir ou diminuir as violências. Porém, o que discutimos são as bases e o pano de fundo de tais ações. Quanto mais se aproximarem do senso comum sobre a paz, tanto mais serão reduzidas de potencial educativo, logo, com impacto limitado, uma vez que serão ações pontuais, sem relação com 
o projeto pedagógico da escola. Além disso, ocorre uma outra situação que é: professores de inúmeras disciplinas, não se sentem mobilizados por um projeto de paz, na medida em que não se veem em condições profissionais para a tarefa. Por isso, grande parte das vezes, isso fica à cargo de um professor rotulado como ingênuo, altruísta, bonzinho, ou que esteja conduzido por algum interesse religioso.

Além de tantas questões preliminares, podemos dizer ainda que, mesmo que estas fossem superadas facilmente, ainda teríamos uma enorme dificuldade para relacionar práticas pedagógicas que pudessem estar no contexto de uma Educação para a Paz. Um relaxamento ou meditação estariam entre estas práticas? Debates sobre os direitos humanos e a injustiça social? Músicas e teatros que simulem situações de violência e não-violência? Sentir a natureza, plantar árvores e discutir a degradação ambiental? As técnicas de mediação de conflitos devem fazer parte? Tudo isso e muito mais? Ou menos? Afinal, quais os critérios ou bases fundamentais para estabelecer um trabalho pedagógico adequado para a Educação para a Paz, que possa contemplar a complexidade da Cultura de Paz?

\section{DO ARGUMENTO PELA PAZ COMO POSSIBILIDADE CIENTÍFICA}

No conjunto amplo e complexo apresentado, uma questão de fundo é sempre recorrente e aparece no argumento de Guimarães (2005, p. 22) que diz:

Nesse contexto, a educação para a paz tem aparecido como um instrumento importante para concretização de uma cultura de paz, emergindo na interlocução da comunidade internacional, não apenas, como uma nova área de pesquisa ou um campo relevante, mas como expressividade da ideia de bem, onde se joga a própria questão do sentido da humanidade e da finalidade da educação.

O cenário brasileiro referente à Cultura de Paz nas escolas se soma às questões referentes à Cultura de Paz no mundo. São dimensões da educação que ocupam, desde há muito tempo, espaço na reflexão e discussão pedagógica. É certo que tais preocupações remetem inicialmente à Europa das décadas iniciais do século XX, depois aos Estados Unidos a partir dos anos 1960. O último estágio da universalização da discussão se dá no início do século XXI especialmente na África, na América Latina e Ásia, particularmente com a divulgação e apoio da Organização das Nações Unidas (ONU), cujo foco foi migrando da violência unicamente entendida como guerra, para todos os problemas estruturais da humanidade, especialmente relacionados à desigualdade social, pobreza, miséria e esgotamento do planeta.

Como notamos, do continente europeu vieram as discussões iniciais, impulsionadas após a I Guerra Mundial (1914-1918). Deste momento destacamos, entre outros, a educadora Maria Montessori, que fala de Educação para a Paz já nos anos 1920 durante suas conferências. Montessori (2004, p. 54) define bem este momento, ainda concebendo a paz como um princípio universal e relacionada à bondade humana:

Paz é um princípio prático da civilização humana e da organização social que está fundamentada na própria natureza humana. A paz não escraviza o homem, pelo contrário, ela o exalta. Não humilha, muito ao contrário, ela o torna consciente de seu poder no universo. E porque está baseada na natureza humana, ela é um princípio universal e constante que vale para todo ser humano. É esse princípio que deve ser nosso guia na elaboração de uma ciência da paz e da educação dos homens para a paz.

Nos Estados Unidos, as discussões são apropriadas e ganham corpo a partir da II Guerra Mundial (1939-1945), já com a criação da ONU (1945) e da Declaração Universal dos Direitos Humanos (1948). Neste momento, Jares (2002) fala da criação do movimento de Pesquisa para a Paz (Peace Research), onde elementos mais densos são discutidos nesta estruturação como campo de pesquisa e ação da paz. Diz Jares (2002, p.82): "O movimento de Pesquisa para a Paz nasce nos Estados Unidos, quando em 1957 aparece a revista Journal of Conflict Resolution". Esta revista deu origem, mais tarde, a um centro de pesquisa de resolução de conflitos (ampliando a pesquisa sobre a paz) na Universidade de Michigan. Não obstante, ressalva Jares (2002) que é na Europa, a partir dos anos 1960 que países como a Suécia e Noruega estabelecem os principais teóricos do movimento Peace Reseach, especialmente com a criação, em 1966 do International Peace Research Institute Oslo, que passa a ser referência mundial para os estudos da paz e conflitos. A partir da Pesquisa pela Paz e da divulgação de estudos, parte deles absorvidos pela ONU em suas perspectivas e documentos, o entendimento 
da paz passa a integrar as demais regiões do planeta. Especialmente as mais afastadas do hemisfério norte.

Deste breve contexto, embora relatado em poucos fatos, mas entendendo toda a estruturação de um campo de conhecimento e pesquisa, desmistifica-se a ideia da Cultura de Paz meramente como expressão religiosa, ou de boa vontade, ou ainda como ingenuidade. Coloca-se a noção de paz no centro do debate entre as questões das múltiplas formas de violência da humanidade, além das guerras, para todos os problemas que são trazidos da periferia do planeta, como a pobreza, a fome, a exploração do trabalho e do meio ambiente. Assim, podemos dizer que a Pesquisa pela Paz, em seu desenvolvimento, trouxe conceitos importantes e experiências ampliadas e profundas ao deslocar-se do eixo Europa-Estados Unidos, ao pesquisar as variadas formas de violência na África, a Ásia e a América Latina.

Passamos a ter um campo de estudos da paz que é abrangente, crítico, interdisciplinar e com alto potencial educacional, de conferir aos estudantes um conhecimento importante sobre o mundo e a sociedade, superando a ideia de práticas milagrosas ou ingênuas rotuladas como Cultura de Paz. É nesse contexto que pensamos a alteração da Lei nº $.9394 / 96$, como oportunidade de reflexão sobre a vida, a sociedade e o planeta de forma macro, para olhar para a própria vida e de sua comunidade, repensando relações humanas e sociais balizadas por violência em processos mais humanos e convivenciais de qualidade, ao mesmo tempo em que reconhece as múltiplas violências sociais, ambientais de seu entorno, para participar de forma cidadã na mudança destes contextos.

\section{DAS QUESTÕES GERAIS DA EDUCAÇÃO PARA A PAZ}

Como argumentamos, o movimento da Pesquisa pela Paz, ao redimensionar a noção de paz, agrega a ela a discussão sobre as múltiplas formas de violência e também o conceito de conflito. Neste movimento, surge a discussão sobre uma Educação para a Paz, que seria o campo pedagógico da ideia de Cultura de Paz. Assim, acreditamos que é exatamente o conceito de Educação para a Paz que merece atenção neste momento de inserção das questões sobre a violência, o bullying e a Cultura de Paz na Lei no ${ }^{\circ}$ 9394/96. Dizemos isso, pelo potencial educativo deste enfoque onde a violência está em reconhecer a origem dos problemas e o conflito é o espaço de mediação de perspectivas, procurando caminhos comuns para a resolução de problemas e a paz, como produto final de um processo dialogado, compartilhado, comunitário e cidadão.

Assim, a Educação para a Paz pode ter papel significativo como elemento educativo, na educação formal ou não-formal, constituindo-se como campo de experiências, análises, avaliações, reflexões e possibilidades no encaminhamento de políticas educacionais. Estas políticas que tenham, como objetivo, tratar das múltiplas violências referentes aos espaços educacionais, na criação de alternativas pedagógicas que favoreçam a não-violência, que melhorem o clima educacional, que qualifiquem as convivências, que evidenciem os direitos humanos e ampliem os olhares das pessoas para a democracia e cidadania. Se concordamos que a violência, ou as violências, são múltiplas, complexas, multifatoriais, igualmente devemos compreender que pensar em Cultura de Paz também é tarefa complexa.

Diante deste contexto difícil em definir a Cultura de Paz, reafirmamos a Educação para a Paz como campo pedagógico. Ou seja, a Cultura de Paz, no contexto escolar, para ser tratada de forma organizada e adequada, precisa reunir seus esforços em torno do conceito de Educação para a Paz. Assim, nos somamos ao que diz Jares (2007, p.46):

A educação para a paz, como dimensão transversal do currículo, afeta todos os seus elementos e etapas educativas. Os temas transversais fazem referência a um tipo de ensinamento que deve ser recolhido em todas as áreas das etapas pedagógicas, o que dimensiona sua influência em todos os elementos do currículo.

Reconhecemos que existem muitos esforços teóricos na tentativa de encontrar equilíbrio conceitual para a Educação para a Paz. Ao mesmo tempo é difícil encontrar aspectos que sintetizem a gama de questões presentes em relação à Cultura de Paz. Fundamentalmente, defendemos a perspectiva de que uma "Cultura de Paz se faz com Educação para a Paz", ou seja, uma Cultura de Paz não é dada por um pensamento universal de harmonia, bondade e felicidade. Antes de tudo, uma Cultura de Paz está no processo de construção e busca de situações que se aproximem 
de uma vida que reúna condições de bem-estar, tanto individual quanto social, diante de um mundo com incontáveis situações de violência e conflito. Portanto, a Educação para a Paz emerge da busca uma reflexão coerente sobre vida e sociedade.

Guimarães (2005) contribui, nesta busca, falando das críticas que a Educação para a Paz recebeu nas últimas décadas, em vários países do mundo, quase todas apontando para o entendimento da paz como algo utilizado politicamente para certa doutrinação ou alienação, no sentido de fugir às raízes dos problemas profundos dos países. No Brasil, o autor cita que as críticas à Educação para a Paz deram-se mais claramente no momento em que eram definidas "algumas bases teóricas e metodológicas e buscavam-se as primeiras experiências do que mais tarde veio a ser chamada na América Latina de educação popular" (GUIMARÃES, 2005, p. 27). Vemos que a origem da crítica, muito presente nos anos da ditadura militar no Brasil (1964-1985) permanecem hoje, onde falar em Educação para a Paz remete a algo que seja contrário à conscientização e a crítica.

Conforme argumentamos até aqui tais críticas, atualmente, não fazem muito sentido, especialmente quando as questões da paz-violências-conflitos são discutidas de maneira crítica e com aprofundamento. O que vale refletir e, constitui-se numa observação necessária, é a forma como as instituições de ensino abordam as questões da Cultura de Paz, muitas vezes relacionadas a um pequeno conjunto de valores, que acabam por reproduzir, formas de perceber o mundo e a vida ainda relacionada às crenças religiosas, por exemplo. Nesse caso, o problema não está na Educação para a Paz em si, mas sim nas concepções de educação subjacentes aos diferentes contextos e espaços educacionais. Assim, para direcionar nossa perspectiva, concordamos com o conceito de Educação para a Paz defendido por Jares (2007, p. 44-45):

[...] concebemos a EP como um processo educativo, contínuo e permanente, fundamentado nos dois conceitos fundadores (concepção de paz positiva e perspectiva criativa do conflito), que, pela aplicação de métodos problematizantes, pretende desenvolver um novo tipo de cultura, a cultura de paz, que ajude as pessoas a entender criticamente a realidade social, desigual, violenta, complexa e conflituosa, para poder ter uma atitude e uma ação diante dela.
Como percebemos, os estudos da paz se baseiam em algumas dimensões conceituais claras segundo Jares (2002): primeiro, a noção de "paz negativa" como aquela paz silenciosa da ditadura ou de várias religiões, mantidas pelo medo e a "paz positiva" como a paz construída nas relações e conflitos tratados positivamente; segundo, a diferenciação entre a violência estrutural e violência direta, que juntas compõe a violência cultural. A "violência estrutural" como sendo as questões sociais, desigualdades e injustiças, sistemas de governo entre outras fragilidades que estarão relacionadas às "violências diretas", como agressão, homicídio, bullying entre tantas. Logo, se o conjunto de violência estrutural e violência direta geram uma cultura de violência, podemos afirmar que uma paz estrutural, fruto de direitos humanos e cidadania elevadas, em sintonia com uma paz direta das pessoas, com a mudança na forma de relações interpessoais, podem contribuir com a criação de uma Cultura de Paz. Nisso, a Educação para a Paz, nas escolas, pode ser um fator altamente contributivo no enfrentamento de comportamentos sociais violentos e também na compreensão e valorização da organização política e democrática da sociedade.

\section{DAS “TRADIÇÕES” TEÓRICAS (CONCEITUAIS) DA EDUCAÇÃO PARA A PAZ}

Em relação às questões conceituais da Educação para a Paz, a contribuição de Guimarães (2005) é importante para sistematizar alguns aspectos. Ele apresenta nove "tradições" ou perspectivas que ocorrem em momentos históricos específicos, demonstrando como a reflexão sobre a paz está relacionada ao contexto e à conjuntura. Assim, a primeira tradição é da dos "movimentos ligados à renovação pedagógica do início do século XX", especialmente na Europa após a I Guerra Mundial (1914-1918), com educadores como Maria Montessori (já apresentada) e Jean Piaget, onde o questionamento se dava também ao ensino voltado à competição e a militarização. Desta forma, a paz seria uma alternativa a este modelo. A segunda tradição apontada pelo autor é a da "UNESCO" (Organização das Nações Unidas para a Educação, a Ciência e a Cultura), onde mostra que a partir de 1945, com a criação da ONU e, 1946, com a criação da UNESCO, é pensada uma educação que vise à paz 
entre os diferentes povos. Este conceito é ampliado ao longo das décadas até que nos anos 1990 as noções de desenvolvimento, democracia e direitos humanos ficam mais presentes, revigorando esta tradição nos atuais estudos da paz.

Na sequência, Guimarães (2005) apresenta a terceira tradição da Educação para a Paz que chama de "movimentos sindicais na guerra fria", presente a partir dos anos 1950, fruto da tensão entre os Estados Unidos e União Soviética. O argumento era o de cessar com o excesso de investimento na indústria bélica e canalizar recursos para o desenvolvimento dos povos e do planeta. Ao mesmo tempo, os movimentos sindicais protagonizaram a luta pelos direitos fundamentais. Na sequência, a quarta tradição, decorrente da II Guerra Mundial, é a "investigação para a paz" (Peace Research), que a partir dos anos 1950 concebe uma ciência da paz, na busca de conhecimentos para promover ações que minimizem os efeitos das violências em duas diversas formas. Este movimento organiza inúmeros conceitos decisivos para o campo da Educação para a Paz, como discussões sobre a conflitologia, paz positiva, paz negativa, violência direta e violência estrutural, conforme já discutimos.

Como a quinta tradição da Educação para a Paz, Guimarães (2005) fala sobre os "movimentos de não-violência" como por exemplo o protagonizado por Mohandas Gandhi (1869-1948) através das ideias de ahimsa (recusa de toda violência) e satyagraha (força que nasce da verdade e do amor). Estes princípios sugerem uma não-violência ativa como intenção final de educar para a paz, considerando a desobediência diante das injustiças e da opressão sofrida pelos diferentes povos. Esta tradição vê os conflitos como oportunidade de mediação sem gerar atitudes violentas. Como sexta tradição da Educação para a Paz, Guimarães (2005) fala das "pedagogias da libertação", surgidas a partir dos anos 1960 na América Latina, sob influência do educador brasileiro Paulo Freire, que teve sua difusão inicialmente nas comunidades eclesiais de base. No mesmo movimento, como consequência, houve a construção das ideias da educação popular. É importante reconhecer Paulo Freire como uma referência aos estudos da paz na atualidade, pela tradição crítica de seu pensamento. Assim, na Educação para a Paz que aproxime a discussão do mundo do texto ao contexto, vemos a contribuição de Freire, registrada por Ana Freire (2006, p. 391):
[...] para Paulo a Paz não é um dado, um fato intrinsecamente humano comum a todos os povos, de quaisquer culturas. Precisamos desde a mais tenra idade formar as crianças na "Cultura da Paz", que necessita desvelar e não esconder, com criticidade ética, as práticas sociais injustas, incentivando a colaboração, a tolerância com o diferente, o espírito de justiça e da solidariedade.

Considerando esta discussão, observamos que a Educação para a Paz amplia o olhar crítico e profundo sobre a sociedade e, especialmente, aos mais vulneráveis do sistema social. Com isso dizemos que nem a paz e nem a violência são questões naturais da sociedade, uma vez que ambas são construções histórico-sociais. Neste sentido, é razoável que, neste momento da educação brasileira, onde temos a oportunidade através da legislação, de elaborar um trabalho consistente envolvendo a paz, que seja explicitado um corpo de conhecimento que pense este conceito, na educação e na formação de professores, como um conjunto de saberes, práticas e experiências passíveis de reflexão, análise e sistematização. Ainda neste caminho, ao receber o Prêmio UNESCO da Educação para a Paz de 1986, Paulo Freire se manifesta, segundo Ana Freire (2006, p. 388) da seguinte forma:

De anônimas gentes, sofridas gentes, exploradas gentes aprendi, sobretudo que a Paz é fundamental, indispensável, mas que a Paz implica lutar por ela. A Paz se cria, se constrói na e pela superação de realidades sociais perversas. A Paz se cria, se constrói na construção incessante da justiça social. Por isso, não creio em nenhum esforço chamado de educação para a Paz que, em lugar de desvelar o mundo das injustiças o torna opaco e tenda a miopizar as suas vítimas.

Paulo Freire é uma referência sempre atual para a reflexão da Educação e também da Educação para a Paz (embora nunca tenha escrito nada especificamente sobre o tema), especialmente na América Latina e particularmente no Brasil, onde é oficialmente o patrono da educação. Cabe ressaltar que, nas últimas décadas, salvo um breve momento de avanço, onde os direitos humanos e a desigualdade social foram tratadas pelas políticas públicas, o continente latino-americano ainda sofre com desigualdades profundas e com injustiças das mais diversas. Isso reforça a opção por uma Educação para a Paz que mantenha uma 
perspectiva crítica em relação à unidade de reflexão entre violência-paz-conflito.

Continuando com Guimarães (2005), a sétima tradição relacionada com a Educação para a Paz é dos "movimentos pedagógicos modernos e contemporâneos", citando a figura de Célestin Freinet (anos 1950) que falava da importância de relação com a sociedade e da negação de uma ilusão, que seria uma sociedade em paz. Para esta tradição, que mais tarde ecoa entre educadores americanos e ingleses (anos 1970 e 1980) a paz seria um desafio pedagógico importante para a educação. A oitava tradição da Educação para a Paz é a perspectiva "socioafetiva" que de acordo com Guimarães $(2005$, p. 81) surge da "da tomada de consciência dos limites das experiências nórdicas e anglo-saxônicas de educação para a paz, centradas na informação e nos conteúdos cognoscitivos". Com isso, abre-se o espaço para valorizar as formas vivencias do trabalho da Educação para a Paz, considerando a ludicidade, a corporeidade e o aspecto relacional. Finalizando, a última tradição da Educação para a Paz analisada por Guimarães (2005), fala da dimensão "holística", que coloca como elementos centrais a consciência e a interioridade da paz no indivíduo. Este movimento nos anos 1960, é relacionado à contracultura, especialmente na Europa e nos Estados Unidos, criticando o modelo ocidental do capitalismo e do consumo, passando a valorizar o orientalismo como condutor das reflexões. A perspectiva holística busca a harmonia entre a intuição, razão, sentimento e sensação, no aprofundamento da consciência interior, que seria responsável em construir a paz nos indivíduos, que coletivamente contribuiriam para a paz geral.

Ao abordar estas tradições da Educação para a Paz, vemos a complexidade e multiplicidade de conhecimento e possibilidades. Lembramos que cada uma delas foi concebida a partir construções históricas, visões de mundo e perspectivas diferentes sobre a paz, a violência e o conflito. Por isso, ao ser explicitado o termo Cultura de Paz na Lei no. 9394/96, há a necessidade de qualificar este campo! Não se trata de "misturar" ou "escolher" uma das tradições, mas sim, observar o momento e a conjuntura nacional, as violências da atualidade que se refletem na escola, as experiências positivas já encaminhadas e, fundamentalmente, deixar claras as balizas mínimas e essenciais para encaminhar as ações de Cultura de Paz nas escolas. É o que diz Guimarães (2005, p.
320): "Qualquer tentativa de reduzir a educação para a paz a apenas uma tradição, sem ao menos acenar para a possibilidade do diferente e do distinto, poderá provocar uma obstrução do processo de cercamento dessa realidade".

Portanto, o ponto fundamental da Educação para a Paz, no momento em que a Cultura de Paz passa a fazer parte da legislação educacional com abrangência nacional, é sobre quais suas dimensões centrais no processo educativo. De acordo com as diferentes abordagens teóricas analisadas, algumas questões são claras: a) abordagens de caráter crítico e social, onde as questões da sociedade são vistas como importantes, b) abordagens com caráter mais individual, olhadas sob o aspecto psicológico e interior do ser humano, c) abordagens relacionadas mais especificamente à educação, d) abordagens vindas de campos complementares à educação. Destas tensões e complementaridades de perspectivas enfatizamos, outra vez, a importância do pensamento de Paulo Freire sobre a paz como elemento crítico da realidade, na medida e que precisa da clareza sobre as desigualdades e conflitos humanos e sociais. Ao mesmo tempo, é importante trazer certa leveza, característica da abordagem holística, para humanizar e referenciar as discussões sociais.

\section{DAS PISTAS METODOLÓGICAS DA EDUCAÇÃO PARA A PAZ}

Como contribuição à perspectiva de possíveis conteúdos relacionados à Educação para a Paz, que possam subsidiar a discussão, trazemos elementos estruturados por pesquisadores espanhóis, que ao longo das últimas décadas, atuaram fortemente em pensar metodologias relacionadas ao processo pedagógico da Cultura de Paz. Isso nos leva a Serrano (2002), Jares (2002) e Tuvilla Rayo (2004). Destacamos que a Educação para a Paz figurou como tema transversal na educação da Espanha entre os anos 1990 anos 2000, o que pode ser uma referência interessante a ser observada neste momento de construção brasileira.

Com Serrano (2002) vemos as seguintes dimensões: 1) a tolerância como valor fundamental, que para a autora figura como princípio central da paz; 2) a relação entre paz, direitos humanos e democracia, que afirma que não é possível a paz sem uma reflexão sobre sociedade democrática e onde os direitos humanos não sejam atendidos; 3) uma sociedade pluralista, 
como respeito fundamental às diversidades; 4) diferenciação entre "paz passiva X paz ativa", valorizando o protagonismo em relação à não-violência e a paz; 5) a transversalidade, como tratamento da paz a partir da possibilidade das diferentes áreas de conhecimento. Com Serrano (2002) vemos que não é possível supor uma Educação para a Paz que não faça um olhar amplo sobre os fenômenos sociais e culturais.

Nos estudos de Tuvilla Rayo (2004) vemos algumas relações próximas e alguns complementos quanto às proposições de Serrano (2002). Para Tuvilla Rayo (2004) temos: 1) a Paz e desenvolvimento humano, onde o argumento é que o ser humano só pode alcançar o desenvolvimento pleno de suas capacidades se houver uma garantia mínima de paz; 2) direitos humanos, natureza e meio ambiente, elementos centrais colocados pelo autor, que ganha ênfase neste momento da humanidade, com a discussão profunda sobre a sustentabilidade; 3) ênfase transdisciplinar, onde para além da disciplinas, supõe a criação de novos conhecimentos como resultado de uma Cultura de Paz; 4) democracia e entendimento internacional, que prevê, além da democracia local, uma abertura para a visão global, não necessariamente globalista, mas sensível às diferentes realidades humanas; 5) transversalidade, reforçando a perspectiva que integre diferentes campos de saberes escolares; 6) educação em valores humanos, educação para a convivência, solidariedade como elementos pedagógicos privilegiados na Educação para a Paz. Como prática pedagógica Tuvilla Rayo (2004) fala sobre o foco em: educação cognitiva-afetiva (compreensão e sensibilização), educação sociopolítica (paz e direitos humanos) e educação ambiental (fauna e flora, demografia, saúde, consumo), através de técnicas cooperativas e de um enfoque socioafetivo, prevendo assembleias, dinâmicas lúdicas (jogos cooperativos, de simulação, de papéis); ênfase nas questões conceituais, procedimentais e sociais de cada atividade.

Os estudos de Jares (2002) também explicitam diversos pontos a ser analisados. Observamos que Jares menciona Paulo Freire em diversos momentos de seu estudo, evidenciando a importância social nos estudos da paz. Para o autor, os elementos estruturantes de uma Educação para a Paz são: 1) a resolução não violenta dos conflitos, afirmando como a Educação para a Paz é estruturada na perspectiva dos conflitos humanos e sociais; 2) explicitar os conflitos de valores, partindo da relação entre valores universais e cotidianos; 3) buscar elementos críticos à sociedade violenta e desigual, quando se percebe a origem das situações; 4) a história da educação para a paz, com a biografia de pacifistas e dos movimentos relacionados à Cultura de Paz. Como elementos pedagógicos, Jares (2002) indica: exercícios de esclarecimento sobre valores humanos, discussão sobre dilemas morais, práticas de resolução de conflitos, práticas de habilidades sociais, estudo de casos, grupos de discussão, jogos de simulação, diálogo a partir de notícias cotidianas, músicas, jogos cooperativos, entre outros.

A partir destes pesquisadores da Educação para a Paz, notamos que existem elementos importantes e questões que podem servir de suporte para a discussão em nossa realidade educacional, guardadas as diferenças conjunturais. Perspectivas contextuais e específicas à parte, o que entendemos é a necessidade de uma discussão séria e abrangente sobre o papel da Cultura de Paz nas escolas. Quanto maior a densidade da discussão, maior a possibilidade de uma Educação para a Paz que realmente contribua com mudanças sociais importantes para as gerações do presente e do futuro. Ao contrário, quanto mais "modismo e senso comum" neste momento, a alteração na Lei nº $.9 .394 / 96$ não terá sentido prático.

\section{DAS CINCO PEDAGOGIAS DA PAZ: PROPOSTA PARA A EDUCAÇÃO PARA A PAZ BRASILEIRA}

Dos argumentos elencados até o momento, é razoável considerar que a Educação para a Paz, como expressão pedagógica da Cultura de Paz, é fortemente marcada por questões como valores humanos, direitos humanos, democracia e desenvolvimento. Portanto, ao pensar em Educação para a Paz na escola precisamos de uma dupla abertura: o entendimento de transversalidade e a perspectiva transdisciplinar. A noção de transdisciplinaridade é importante no sentido exposto por Nicolescu (2000) sobre as quatro flechas do conhecimento: disciplinaridade, multidisciplinaridade, interdisciplinaridade e transdisciplinaridade. Julgamos esta observação necessária, uma vez que a Cultura de Paz na escola precisa ser tratada como um campo aberto, onde as diferentes disciplinas preservem suas caminhadas específicas, mas, ao mesmo tempo estejam abertas às interações com as demais e até para a 
co-criação de outras formas de abordagem. Dizemos isso, porque no campo da paz, também circulam conhecimentos populares, como das visões religiosas, familiares, comunitárias, fruto das convivências entre as pessoas e, que merecem ser valorizadas. A esse respeito, Morin (2013, p.193) diz:

Um novo sistema de educação, fundado da religação, e por isso, radicalmente diferente do atual, deveria substituí-lo. Esse sistema permitiria favorecer a capacidade da mente para pensar os problemas individuais e coletivos em sua complexidade. Ele sensibilizaria para a ambiguidade e ambivalências, e ensinaria a associar os termos antagônicos para apreender uma complexidade.

Já o caráter transversal possibilitaria à Educação para a Paz ser um tema gerador que envolvesse diferentes áreas e pessoas em discussões ampliadas. Vejamos um exemplo: o tema "desarmamento", ao invés de ser tratado unicamente como uma questão de polícia, poderia ser entendido numa perspectiva de segurança pública e comunitária, dentro de uma proposta ampla de Educação para a Paz, num paradigma integrador da Cultura de Paz na sociedade. Assim se assemelhariam os "projetos de valores nas escolas", "projetos de meio ambiente", "projetos de diversidade", que muitas vezes são tratados em cima de perspectivas clássicas da educação, como aproveitar datas (no Brasil) como o "dia do índio", "dia da consciência negra" e "dia da árvore". De maneira geral, todos estes projetos buscam a conscientização, sensibilização e ações que contribuam para uma Cultura de Paz. Porém, será que garantem que a noção de Educação para a Paz, como campo de crítica aos problemas de forma ampla, relacional e integrada sejam desenvolvidos? Ou ficam fragmentos nas "matérias" tratadas isoladamente? Mais ainda, nessa fragmentação não correremos o risco de tentar encontrar especialistas em conteúdos de paz? Portanto, é necessário, na definição e nos olhares para o que efetivamente será ensinado com a Educação para a Paz, a noção de complexidade e, no caso da proposição de elementos pedagógicos, a ideia de transdiciplinaridade a ser tomada como condição de ligação/religação das áreas, num mesmo movimento de intencionalidade e protagonismo docente na perspectiva de transversalidade. Esta perspectiva complexa, multidisciplinar e muito próxima ao que propomos como paradigma da Cultura de Paz é evidenciada por Suanno (2015, p.109):
O olhar transdisciplinar é uma nova maneira de pensar, de sentir, de perceber a realidade e interagir que se projeta na vida pessoal, profissional e social, por isso que essa religação ecológica entre indivíduo, a sociedade e a natureza têm suas consequências em uma cidadania planetária constituída por seres humanos dotados de direitos e liberdades. Práticas transdisciplinares baseadas no respeito, na convivência, na conservação dos meios naturais, na melhoria das condições de vida, no consumo consciente e na produção que não menospreze os direitos humanos nem o bem-estar psicossocial da pessoa fazem-se fundamentais nas atuais realidades social, institucional e educacional.

Considerando estas questões e fazendo uma ponte com os "sete saberes da educação do futuro" propostos por Morin (2011) que são: as cegueiras do conhecimento, o conhecimento pertinente, ensinar a condição humana, ensinar a identidade terrena, enfrentar as incertezas, ensinar a compreensão e a ética do gênero humano, passamos a delinear as "Cinco Pedagogias da Paz", propostas por Salles Filho $(2016)^{1}$. Ressaltamos que as pedagogias da paz, propostas de forma integrada, tem sentido especialmente se pensadas à luz do pensamento complexo de Edgar Morin. Discorreremos brevemente sobre a perspectiva básica das cinco pedagogias, procurando situar como estão relacionadas a uma proposta de Educação para a Paz, baseada em elementos discutidos ao longo do texto.

Destacamos como o primeiro eixo, ou a primeira pedagogia proposta por Salles Filho (2016), a Pedagogia dos Valores Humanos, evidenciando que ela tem seu aspecto chave entre os pesquisadores da Educação para a Paz. Os valores humanos estão na base do comportamento humano, em todos os pensamentos e ações humanas e, criam/recriam a sociedade. Podemos dizer que os valores humanos compõem a própria história e o desenvolvimento da humanidade, sempre no fluxo que aponta valores que podem ser próximos, ou contraditórios, ou em construção. Como reflexo para entender os valores humanos, enfatizamos

\footnotetext{
As "cinco pedagogias da paz" são sistematizadas como modelo teórico-metodológico para a Educação para a Paz, na pesquisa desenvolvida como tese de doutorado intitulada "Cultura de Paz e Educação para a Paz: olhares a partir da teoria da complexidade de Edgar Morin, (2016), aprovada no Programa de Pós-Graduação em Educação da Universidade Estadual de Ponta Grossa, Paraná.
} 
o posicionamento pertinente de Braithwaite e Blamey (2006, p.187):

A qualidade consensual dos valores emerge do ponto de vista compartilhado de que são produtos culturais e de que sua percebida desejabilidade foi adquirida no processo de socialização. Isso não significa negar que os indivíduos e grupos deem aos valores interpretações particulares. Por exemplo, deve haver um amplo consenso sobre o valor mundo de paz (grifo nosso), mas as pessoas se diferenciarão à medida que veem que a paz é alcançável mediante ações econômicas, questões militares, negociação, comprometimento ou dando a outra face em determinada situação.

Portanto, na busca de equilíbrio entre valores seculares e outros valores cotidianos, criados e recriados, em mutação nas diferentes culturas e povos, em grupos comunitários diversos, que encontraremos as bases para a construção dos direitos humanos. Assim, de forma interligada entende-se a Pedagogia dos Direitos Humanos, de acordo com Salles Filho (2016) não apenas como a informação e ensino da "Declaração dos Direitos Humanos Universais", mas como tudo aquilo que se apresenta como "direito à paz” (TUVILLA RAYO, 2004) na perspectiva de tudo o que historicamente foi agregado no desenvolvimento de práticas, convenções e leis destinadas à promoção e preservação da vida em todos os sentidos, na dimensão individual, social e planetária. Portanto não basta informar sobre Direitos Humanos, sem as condições para que sejam efetivamente postos em prática contra as injustiças e desigualdades da comunidade global. A relação entre valores humanos e direitos humanos fica ainda mais nítida quando Bar-Tal (2002, p. 28 apud FERREIRA; SALGADO, 2012, p. 57) fala dos projetos de Educação para a Paz:

O objetivo é diminuir, ou mesmo erradicar, uma variedade de maldades humanas, variando entre a injustiça, a desigualdade, o preconceito e a intolerância ou o abuso dos direitos humanos, a destruição ambiental, o conflito violento, a guerra e outras maldades, com vista a criar um mundo de justiça igualdade, tolerância, direitos humanos, qualidade ambiental e outros atributos positivos.

Ao mesmo tempo em que é necessário buscar equilíbrio entre valores universais e locais, temos que considerar profundas diferenças históricas, sociais, econômicas das diferentes culturas e dos diferentes países. Portanto, parece natural que muitas questões em relação aos Valores Humanos e Direitos Humanos sejam palco de debates e divergências. Os direitos humanos são uma "história viva" entre os avanços e recuos na história dos povos, entre momentos de cuidado e atenção com a vida, até seu contrário, as violações que surgem com a violência e a morte, direta ou indireta. Nesse sentido, colocamos a Pedagogia dos Direitos Humanos como uma das dimensões no projeto de Educação para a Paz, menos por seu sentido pragmático e ideal, mais pela sua capacidade de mobilizar para questões urgentes na vida cotidiana (SALLES FILHO, 2016). E como dizem Ortega e Del Rey (2002, p.15):

Em uma sociedade como a atual, submetida a mudanças tecnológicas tão aceleradas, é difícil saber quais vão ser as necessidades imediatas para o dia de amanhã; do mesmo modo, é difícil tomar decisões sobre onde colocar o rol de aspirações de qualidade de vida. O que acontece no âmbito das sociedades desenvolvidas é que, quanto maior o estado de bem-estar, maior consciência social se produz com relação à melhoria das condições de vida. Já no caso dos que vivem nas regiões pobres e muitos pobres, ocorre algo diferente, ou seja, a aspiração justa costuma ser a busca de um mínimo que permita ir resolvendo as necessidades básicas, sem a qual não será possível falar do respeito aos Direitos Humanos.

Estas perspectivas e oposições, os conflitos, podem nos levar à múltiplas violências, como já dissemos. Por isso, é estabelecido o terceiro eixo da Educação para a Paz, a Pedagogia da Conflitologia, entendida por Salles Filho (2016) como caminho pedagógico para o tratamento das inúmeras diferenças de pensamento entre as pessoas. Temas como resolução de conflitos, mediação, práticas restaurativas, avançam de forma consistente nas últimas décadas, como alternativas às "vias de fato", quando a intolerância supera o respeito à diversidade. A conflitologia, também como campo de conhecimento, nessa relação integrada aos valores e direitos gera a sensibilização ao outro ser humano e às outras culturas, humanizando relacionamentos, pensamentos, ações e reações. Ainda para Salles Filho (2016), os valores humanos, os direitos humanos e a conflitologia podem se constituir em pedagogias próprias, mas que, articuladas na perspectiva da complexidade promovem uma mudança de 
sentido do ser humano no mundo. Para Galtung (2006) os conflitos precisam ser transformados, ou seja, redimensionados criativamente prevendo, de início, uma despolarização no sentido de não-enfrentamento, pois este é o principal inibidor do diálogo e da empatia. Em seguida, deve haver a humanização dos fatos e das situações, mostrando os limites de cada um diante de situações difíceis colocadas pelas relações e pelos contextos. Como bem resume Maya (2005, p.77):

Educar para a Paz e a convivência não é erradicar o conflito. É impossível erradicá-lo, pois ele é um fenômeno universal inerente ao ser humano e não deve ser visto como algo negativo. Graças aos conflitos, as sociedades progridem e são alcançadas melhoras para os seres humanos. O que é realmente negativo é a violência pela qual são enfrentados os conflitos. Educar para a Paz e a convivência é educar para a administração alternativa do conflito, é educar para habilidades necessárias que permitam tratar os conflitos de forma não-violenta.

Neste sentido, Galtung apresenta a seguinte relação "paz = despolarização + humanização" (2006, p.107) que vem acompanhada de possibilidades pedagógicas concretas, relacionadas pelo próprio Galtung (2006) em quatro pontos: 1) transformação de conflitos: que visa clarificar melhor as situações de conflito; 2) construção da paz: que tende a evitar a polarização e a desumanização nas atitudes e comportamentos; 3) manutenção da paz: com a ideia da sustentabilidade de situações positivas que atenuem a violência e a reconciliação; 4) restaurando os conflitos, quebrando o círculo vicioso da violência.

Ao falar de "ser humano no mundo", pensamos também em cidadania planetária, como aponta Morin (2011) e naquilo que Tuvilla Rayo (2004) nominou como "ecopacificar" a sociedade. Para Salles Filho (2016), deste conjunto de ações do ser humano no mundo, sociedade e planeta, que também precisa ser preservado nos seus recursos naturais, enfrentando inúmeras catástrofes ambientais nos últimos anos, é que se integra à Educação para a Paz, um quarto eixo, a Pedagogia da Ecoformação, entendida como a união entre "educação ambiental junto com uma educação para ao desenvolvimento sustentável, ou a educação para os direitos humanos e a paz. Isso tudo passa pela educação para a solidariedade, do compromisso com toda a terra e com os seus habitantes" (NAVARRA, 2008, p. 251).
Portanto, para Salles Filho (2016) a ecoformação buscará e relação ser humano/ser planetário, não somente como um conjunto de práticas ecologicamente sustentáveis do meio ambiente, mas como o redimensionamento da ideia de preservar e sustentar a vida de forma mais plena e realizada com todas as formas de existência do planeta. Cuidar da água, assim, é buscar a paz, no sentido que o descuido com ela levará à morte. Tratar as árvores com humanidade significa prevenir a degradação do meio ambiente, que adiante poderá causar desmoronamentos e morte, além de prejuízo às pessoas em zonas de risco. No limite, a ecoformação aprofunda a relação homem e natureza naquilo que mais existe de sensibilidade, o que poderíamos relacionar com a perspectiva da espiritualidade, não como religião, mas como transcendência. Como fala Suanno (2014, p.175) a ecoformação se constrói com o desenvolvimento de "uma educação ambiental, também atenta aos direitos humanos e à paz". A síntese dessa ideia aparece com Boff $(2002$, p. 22):

O cuidado com a Terra representa o global. O cuidado com o próprio nicho ecológico representa o local. O ser humano tem os pés no chão (local) e a cabeça aberta para o infinito (global). O coração une chão e infinito, abismo e estrelas, local e global. A lógica do coração, capacidade de encontrar a justa medida e construir o equilíbrio dinâmico.

Conforme Salles Filho (2016), os debates sobre a preservação da vida e do planeta, também estão sob a tensão de divergências de poder geográfico e econômico (conflitologia), envolvem legislação e busca conjunta pela diminuição dos impactos (direitos humanos), além da construção de novos valores, voltados à espiritualidade e à sustentabilidade (valores humanos). Da articulação destes quatro eixos: Pedagogia dos Valores Humanos, Pedagogia dos Direitos Humanos, Pedagogia da Conflitologia e Pedagogia da Ecoformação, acreditamos que, na perspectiva da complexidade, conseguimos intercambiar os elementos propostos pela Educação para a Paz com os saberes da educação para ao século XXI. Porém, abre-se uma outra necessidade, como fazer para que isso ocorra na prática educacional? Aqui a afirmação de Rabbani (2003, p. 65) é precisa: “Apenas informar sobre a paz, as distintas formas de violência, a história da guerra e a importância do desarme ou de uma conduta eticamente correta, tampouco conleva 
à paz". Isso significa dizer que precisamos alterar as formas de viver e conviver nas escolas, nas relações, para verdadeiramente pensarmos em um paradigma de Cultura de Paz (SALLES FILHO, 2016)

Estas reflexões nos levam ao quinto eixo proposto por Salles Filho (2016), articulados a partir dos demais, que é a Pedagogia das Vivências/ Convivências. Esta pedagogia da prática pedagógica da Educação para a Paz aponta recursos educacionais que estarão em estreita sintonia com os pressupostos das demais pedagogias da paz e que, tem na ludicidade e na corporeidade, algumas de suas bases. Nas palavras de Moraes (2010, p. 54): "Cognição e vida não estão separadas, e o conhecimento acontece no cotidiano da vida, no viver/conviver" (MORAES, 2010, p. 54). Ainda Moraes (2010, p. 41) afirma que "a educação é um processo de transformação na convivência" e continua:

\section{É no processo de transformação na convivência que o ser humano conserva, ou não, sua humanidade. $O$ mesmo ocorre durante o processo educacional, a partir do qual nos transformamos, congruentes com a transformação do outro no espaço de convivência. E o que nos faz humanos, segundo esta teoria, é nosso viver como seres linguageantes, cooperativos e amorosos, com consciência de si e com consciência social, no respeito por si mesmo e pelos outros.}

Observamos que nesta proposta é fundamental transformar as convivências para caminhar na direção de uma Educação para a Paz. Ao repensar as vivências e convivências, alteramos a forma de conceber o processo humano e educacional, supondo a integralidade do ser humano (corpo, mente e espírito), que religa sua essência e existência. A Pedagogia das vivências/ convivências permite que o ser humano aprenda a partir de seu lugar, com suas próprias experiências e com seus relacionamentos. Assim, não há necessariamente conhecimento cognitivo e enciclopédico, apenas como fruto da lógica e racionalização. Trata-se de estar presente na própria vida, com a corporeidade, nas próprias experiências humanas e sociais, inclusive a partir das relações escolares.

\section{CONSIDERAÇÕES}

O fato concreto que impulsiona este artigo é a alteração na Lei de Diretrizes e Bases da Educação
Nacional (LEI Nº. 9.394/96) que inseriu a dimensão da prevenção das violências e promoção da cultura de paz em seu texto oficial. Especificamente, tratamos da questão da Cultura de Paz por ser um campo frágil na discussão educacional brasileira, não obstante já possua prática pedagógicas em diversos estados e em muitas escolas. Porém, a produção acadêmica sobre estas experiências, bem como sobre as questões teóricas relacionadas aos estudos da paz, ainda são restritas a poucos grupos no país, o que não permite um consenso mínimo sobre quais os indicadores essenciais necessários para programas de Cultura de Paz, que efetivamente contemplem a alteração na legislação.

Por isso, tratamos da Educação para a Paz como discussão educacional já estabelecida, com referências teóricas e metodológicas, vindas de seu desenvolvimento histórico em outros países, particularmente na Espanha, onde este aparato conceitual foi fundamental para construir propostas pedagógicas relevantes. Aqui temos duas questões importantes: a primeira é considerar e valorizar esta construção de qualidade e consistência apresentada pelos teóricos analisados; a segunda é considerar a realidade brasileira atual, tanto na conjuntura referente às múltiplas violências escolares quanto ao discurso que a educação brasileira vem produzindo nas últimas décadas, muito marcado pelas referências à cidadania, formação humana e social.

A partir disso, apresentamos uma proposta de Educação para a Paz já construída dentro destas perspectivas, tanto da realidade brasileira como da atenção às contribuições do campo de conhecimento já estabelecidas. Com isso, objetivamos trazer mais argumentos e maiores reflexões que subsidiem este momento importante da educação brasileira, tanto com a possibilidade de prevenção das violências e combate ao bullying como questões diretas, porém sustentadas pela dimensão da Educação para a Paz. Como argumentamos ao longo do texto, uma Educação para a Paz que relaciona a paz como um aprendizado da relação dos valores humanos com os direitos humanos, pressupondo o processo de mediação dos conflitos e redimensionado pela ideia de sustentabilidade da vida e do planeta, através de relações convivenciais mais humanas. Em poucas palavras, uma Educação para a Paz que seja importante para contribuir com uma Cultura de Paz possível, sem ingenuidade, mas com compromisso com o presente e o futuro. 


\section{REFERÊNCIAS}

BRAITHWAITE, V.; BLAMEY, R. Consenso, estabilidade e significado nos valores sociais abstratos. In: ROS, M.; GOUVEIA, V. (Orgs). Psicologia social dos valores humanos: desenvolvimentos teóricos, metodológicos e aplicados. São Paulo: Senac São Paulo, 2006. p. 181-206.

BOFF, Leonardo. Saber cuidar: ética do humano compaixão pela terra. 2. ed. Petrópolis: Vozes, 2002.

BRASIL. Lei Federal $n^{\circ}$ 9.394, de 20 de dezembro de 1996. Estabelece as diretrizes e bases da educação nacional. Disponível em: < http://portal.mec.gov.br/seesp/arquivos/ pdf/lei9394_ldbn1.pdf > Acesso em: 17/05/2018

Lei Federal n 13.663, de 14 de maio de 2018.

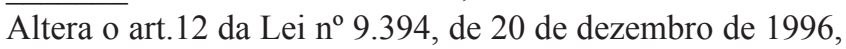
para incluir a promoção de medidas de conscientização, de prevenção e de combate a todos os tipos de violência e a promoção da cultura de paz entre as incumbências dos estabelecimentos de ensino. Brasília, DF, 14. Mai. 2018.

Lei Federal no 13.185, de 6 de novembro de 2015. Institui o Programa de Combate à Intimidação Sistemática (Bullying). Brasília, DF, 6. Nov. 2015. Disponível em: < http://www.planalto.gov.br/ccivil_03/_ato2015-2018/2015/ lei/113185.htm > Acesso em: 17/05/2018

Lei Federal $n^{\circ}$ 13.005, de 25 de junho de 2014. Aprova o Plano Nacional de Educação - PNE e dá outras providências. Brasília, DF, 25. Jun. 2014. Disponível em: < http://www.planalto.gov.br/ccivil_03/_ato2011-2014/2014/ lei/113005.htm >. Acesso em: 17/05/2018.

FERREIRA. Tiago B. S.; SALGADO, João M. C. F. Educação para a Paz: uma perspectiva dialógica. In: BRANCO, Ângela M. C. U. A; OLIVEIRA, Maria C. S. L. (orgs.) Diversidade e Cultura de Paz na escola: contribuições da perspectiva sociocultural. Porto Alegre: Mediação, 2012. p. 51-65.

FREIRE, Ana M. Educação para a paz segundo Paulo Freire. In: Revista Educação, Pontifícia Universidade Católica do Rio Grande do Sul. Porto Alegre: PUC/RS, ano XXIX, n. 2, v. 59, p. 387-393, maio/agosto, 2006.

GALTUNG, Johan. Transcender e transformar: uma introdução ao trabalho de conflitos. Tradução de Antonio Carlos da Silva Rosa. São Paulo: Palas Athena, 2006.

GUIMARÃES, Marcelo R. Educação para a Paz: sentidos e dilemas. Caxias do Sul: Educs, 2005.

JARES, Xesús R. Educação para a paz: sua teoria e sua Prática. 2.ed. Porto Alegre: Artmed, 2002.

JARES, Xesús R. Educar para a paz em tempos dificeis. São Paulo: Palas Athenas, 2007.

MAYA, Beatriz M. Educar para a administração alternativa de conflitos como via de aprofundamento da democracia. In: VINYAMATA, Eduard (org.). Aprender a partir do conflito: conflitologia e educação. Porto Alegre: Artmed, 2005. p. 7583.

MORIN, Edgar. Os sete saberes necessários à educação do futuro. 2 ed. rev. Tradução de Catarina Eleonora F. da Silva e Jeanne Sawaya; revisão técnica de Edgard Assis de Carvalho. São Paulo: Cortez ; Brasília, DF: Unesco, 2011.

. A via para o futuro da humanidade. Tradução de Edgard Assis de Carvalho e Mariza Perassi Bosco. Rio de Janeiro: Bertrand Brasil, 2013.

MORAES. Maria C. Ambientes de aprendizagem como expressão de convivência e transformação. In: MORAES, Maria C.; BATALlOSO NAVAS, Juan M. (orgs.) Complexidade e transdisciplinaridade em educação: teoria e prática docente. Rio de Janeiro: Wak Editora, 2010. p. 21-62.

MONTESSORI, Maria. A educação e a paz. Campinas: Papirus, 2004

NAVARRA, Juan M. Ecoformação: além da educação ambiental. In: LA TORRE, S. (org). Transdisciplinaridade e Ecoformação: um novo olhar sobre a educação. São Paulo: TRIOM, 2008. p. 235 - 260.

NICOLESCU,Basarab.Omanifestodatransdisciplinaridade. Tradução de Lúcia Pereira de Souza. São Paulo: Triom, 1999. 153p.

ORTEGA, Rosário; DEL REY. Rosário. Estratégias educativas para a prevenção da violência. Tradução de Joaquim Ozório. Brasília: UNESCO, UCB, 2002.

RABBANI, Martha J. Educação para a Paz: desenvolvimento histórico, objetivos e metodologia. In: MILANI, F. (org.) Cultura de Paz: estratégias, mapas e bússolas. Salvador: INPAZ, 2003. p. 63-95.

SALLES FILHO, Nei A. Cultura de Paz e Educação para a Paz: olhares a partir da teoria da complexidade de Edgar Morin. Tese de Doutorado. Programa de Pós-Graduação em Educação da Universidade Estadual de Ponta Grossa, Paraná, 2016.

SUANNO, João H. Ecoformação, transdisciplinaridade e criatividade: a escola e a formação do cidadão no século XXI. In: MORAES, Maria C.; SUANNO, João H. (orgs.) O pensar complexo na educação: sustentabilidade, transdisciplinaridade e criatividade. Rio de Janeiro: Wak, 2014. p. 205-210.

SUANNO, Marilza V. R. Educar em prol da Macrotransição: emerge uma didática complexa e transdisciplinar. In: BEHRENS, Marilda A.; ENS, Romilda T. Complexidade e transdisciplinaridade: novas perspectivas teóricas e práticas para a formação de professores. Curitiba: Appris, 2015. p. 199-214.

TUVILlA RAYO, Jose. Educação em Direitos Humanos: rumo a uma perspectiva global. Porto Alegre: Artmed, 2004. 